\title{
APPLICATION OF VOLTAGE PHASE ANGLE CONTROL IN POWER SYSTEM WITH UNEVENLY LOADED SUPPLY NETWORK
}

\author{
Nariman Rahmanov, Osman Ilyasov, Huseyngulu Guliyev*, \\ Azerbaijan Scientific-Research and Designed-Prospecting Institute of Energetics, OSC "Azerenerji", Baku, Azerbaijan
}

\begin{abstract}
In real power system situations of uneven loading of supply lines included in the section, forming connection between the source and the power system or separate dedicated load node, often occur. In such situations one of power transmission lines (PTL) will be loaded below the nominal installed capacity, while the other parallel communication line will be overloaded. Elimination of uneven load in PTL can be performed by the phase angle control between the voltages at the beginning and end of the connection. One of the effective means for the phase angle control is a phase-shifting transformer (PST), the control of which is provided by the redistribution of power flows in individual PTLs of the section with the elimination of their uneven loading. On the example of simulation and computational experiments carried out in the power system of Azerbaijan, the effectiveness of use of voltage phase angle control in the power system with a significant uneven loading in the controlled sections of the supply network of the system is shown. Analysis of the effect of elimination of the unevenness on reducing losses in the network and increasing the efficiency of using power generation at stations is given.
\end{abstract}

\section{INTRODUCTION}

The control of power flows in the electrical networks of the power system is the main method of maintaining the reliability and efficiency of its operation. In supply and distribution high voltage networks, the power flow control is carried out by the control of voltage and reactive power in the controlled nodes of these networks. One of the properties of the electrical networks of the power system, which determine the need for the prompt redistribution of power flows, is the heterogeneity, irregularity of loading of high-voltage lines in the supply and distribution networks, as well as the periodic necessity for the mode correction to meet the conditions for minimum losses in these networks.

To solve the problems of the power system mode control, taking into account these properties, various methods and software and hardware have been developed. For example, to eliminate the heterogeneity, various approaches, based on disconnection of circuit of closed networks, are proposed. [1]. Disconnection methods do not always justify themselves due to the high cost of practical implementation and significant weakening of the reliability of power supply.

Another group of approaches for the elimination of the heterogeneity of closed electrical networks is based on the forced change of the network diagram parameters by connecting FACTS (Flexible Alternative Current Transmission Systems) facilities [2-7]. One of the options for this approach is the longitudinal compensation of the PTL parameters in the supply network [8].

Studies on the application of voltage phase control in lines forming a parallel connection between the source and the power system and having different degrees of uneven loading of these PTLs are carried out in the work. One of the means of voltage control in order to redistribute the flows of active and reactive powers in the network, to eliminate the irregularity of the loading of the lines in the sections, providing the power transfer from power plants to the power system, are PST [9-15].

The voltage is regulated at the beginning of the supply line by magnitude and phase between the voltage vectors at the beginning and end of the power transmission.

\section{MODEL AND CIRCUIT FOR VOLTAGE PHASE ANGLE CONTROL IN THE POWER SYSTEM BASED ON PST}

The active power flow control of the line can be performed by changing the phase angle or the reactance of this line. The change of reactance can be implemented by placing capacitive elements along the line for the compensation of the line inductance. In addition to the line inductance compensation, activation of capacitance can be used to suppress fluctuations of the transmitted power.

Basically, for the flow redistribution in the transmission network and reduction of loading of one of the lines outgoing from the source, the angle phase control between the voltage vectors at the beginning and end of the line is applied. The power flow in PTL can be increased by increasing the phase angle. The value of additional angle increment is controlled in a certain specified interval. In accordance with the relationship between the phase angle and the additional voltage phase angle shift towards increase, two types of regulation are offered [16]:

- regulation of the phase angle and the voltage value (the angle between the voltage phase and the additional phase angle increment varies between $0^{\circ}$ and $90^{\circ}$;

- phase angle regulation (angle between voltages $90^{\circ}$ ).

Supply network diagram consisting of parallel PTLs, in one of which the connection between the source (system 1) and the consumption node (load 2) is

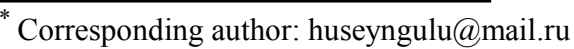


performed on different voltage class with the connection of the PST is shown in Fig.1.

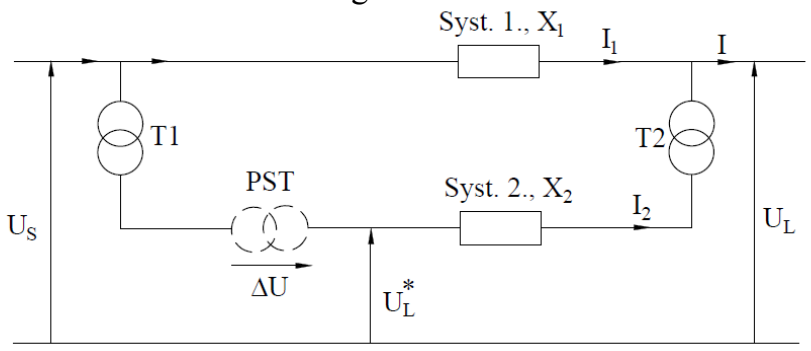

Fig.1. Typical diagram of two parallel supply power transmission systems

In the absence of a switched-on PST, the currents in the lines $I_{1}$ and $I_{2}$ will be distributed in proportion to the values of their impedance, respectively [16]:

$$
\begin{aligned}
& I_{1}=\frac{X_{2}}{X_{1}+X_{2}} \cdot I \\
& I_{2}=\frac{X_{1}}{X_{1}+X_{2}} \cdot I
\end{aligned}
$$

With increase in power in PTL 2, additional voltage $\Delta U$ must be applied for the compensation of the voltage drop in this PTL.

In principle, the source can be connected to either of the two parallel systems. Vector diagrams of voltages for both cases of FPT connection are shown in Fig.2. Fig. 2 corresponds to the case of connection to PTL 2 (Fig. 1), which has a high impedance. The additional voltage reduces the voltage drop in the PTL 2.

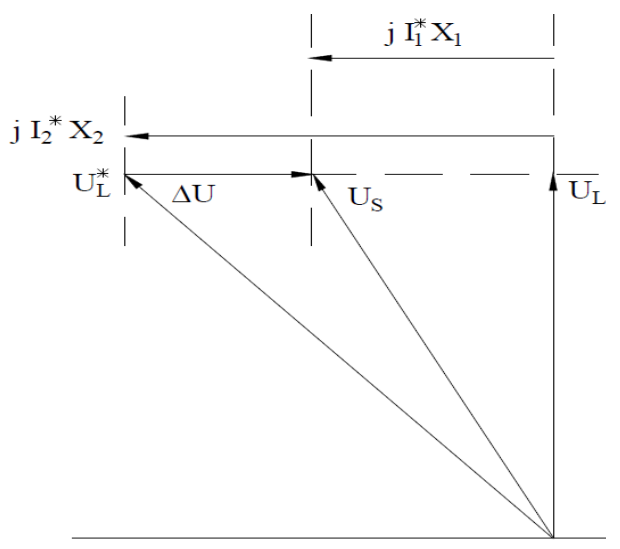

Fig.2. Vector voltage diagram when using PST (PTL 2 phase lead - $U_{L}^{*}$ advances $U_{S}$ )

Another very important application of PST is the active power flow control between two large independent power pool (PP) systems (Fig. 3). The leading phase angle is required to maintain the power flow from power pool 1 to power pool 2 .

$$
U_{S}+\Delta U-I^{*} j X-U_{L}=0
$$

at

$$
\begin{gathered}
U_{S}=U_{L}=U \\
\Delta U-I^{*} j X=0
\end{gathered}
$$

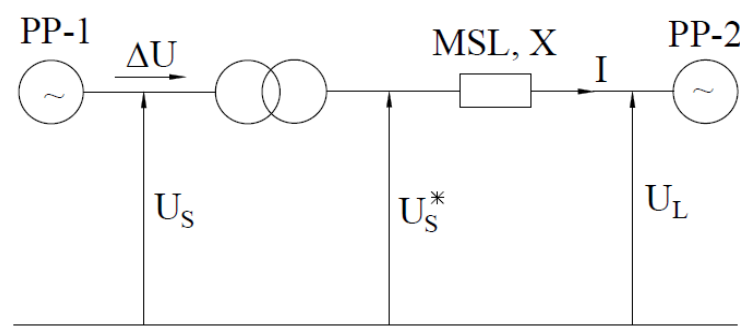

Fig.3. Intersystem communication

\section{THE USE OF VOLTAGE PHASE ANGLE CONTROL FORTHE REDISTRIBUTIONOF THE ACTIVE POWER FLOW IN SUPPLY NETWORK OF THE AZERENERJI SYSTEM}

The studies were carried out for a section of the $220 / 110 \mathrm{kV}$ backbone network connecting the "Shimal" gas turbine station with the power system through parallel operating $110 \mathrm{kV}$ and $220 \mathrm{kV}$ transmission lines.

The block diagram of the investigated power district of $220 / 110 \mathrm{kV}$ power system is shown in Fig. 4. The installed capacity of "Shimal" PP is $2 \times 400 \mathrm{MW}$ ("Shimal"PP-1 - 400 MW, "Shimal"PP-2 - 400 MW). The power plant is connected to $220 / 110 \mathrm{kV}$ "Govsan" SS by lines 3, 4 of $220 \mathrm{kV}$ "Govsan", from 220/110 kV "Zabrat" SS by lines 3, 4 of $220 \mathrm{kV}$ "Zabrat", as well as $110 / 10 \mathrm{kV}$ substations "Mashtaga", "Gala" and "Dyubendi" by lines 1-5 of $110 \mathrm{kV}$ "Shimal".

The "Shimal-2"PP, being put into operation, had a significant effect on the power flow in the $110 \mathrm{kV}$ electric network of the power district. At the same time, the $220 / 110 \mathrm{kV}$ power district is characterized by largen on uniformities, since the $x / r$ ratio for the branches in the circuits differs by more than 10 times (where, $x-$ inductive resistance of the branches; $r$-active resistance of the branches).

As a result of the influence of these factors in the power district, one of the most striking problems existing in modern power systems arises - the limitation of the carrying capacity of electrical networks associated with overloading of $110 \mathrm{kV}$ transmission lines [15]. At the same time, under loading of power lines of higher voltage $(220 \mathrm{kV})$ occurs. For example, the calculations performed according to the normal scheme, based on measurement data during the summer maximum of the power system $(07 / 19 / 2019,21: 00)$, indicate that the load of lines 4 and 5 of $110 \mathrm{kV}$ "Shimal" is $72.1 \mathrm{MW}(390 \mathrm{~A})$ and 71.1 MW(390A), respectively, while the load of lines 3 and 4 of $220 \mathrm{kV}$ "Govsan" was $103.8 \mathrm{MW}$ (310A).

Due to the limitation of the carrying capacity of 110 $\mathrm{kV}$ electrical networks in the area of the "Shimal-1" and "Shimal-2" power plants, there is a threat of exceeding the permissible values of operating parameters in repair and post-emergency modes and, accordingly, it becomes necessary to limit the power output of the power plant or the consumers' load. For example, during the emergency shutdown of PTL-4 of $110 \mathrm{kV}$ "Shimal", $110 \mathrm{kV}$ "Shimal" PTL is loaded up to $99.3 \mathrm{MW}$ (545 A) and at the same time the loads of PTLs 3 and 4 of $220 \mathrm{kV}$ "Govsan" is 112.6 MW (340 A). At the same time, when 
one of the PTLs 4 and 5 of $110 \mathrm{kV}$ "Shimal" is taken out for repair or emergency shutdown, the load of PTL, remaining in operation, depending on the air temperature exceeds the permissible limit. Therefore, in such cases the application of restrictions is inevitable.

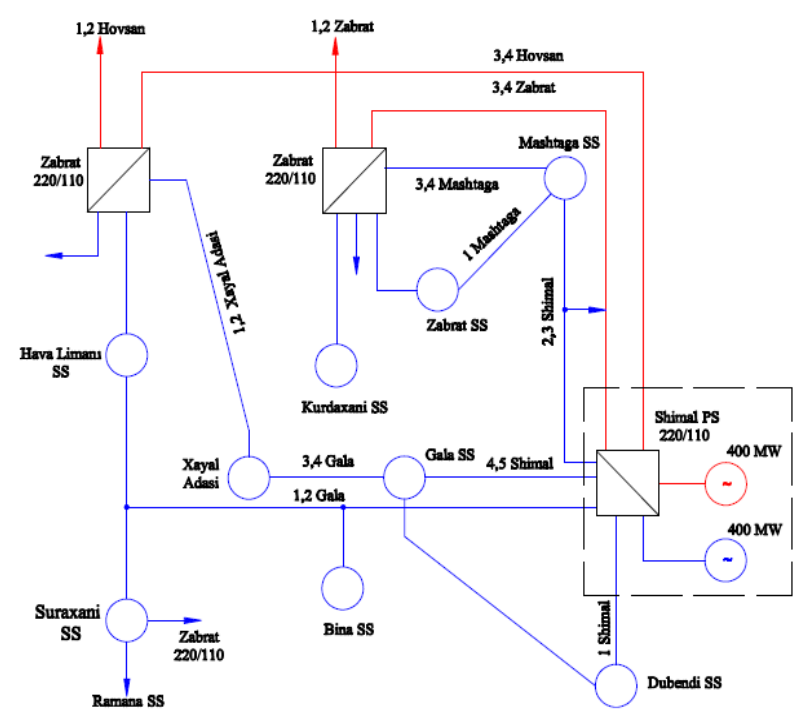

Fig. 4. Scheme of a section of a backbone network of $220 / 110 \mathrm{kV}$ Azerenerji system

\section{ANALYSIS OF THE RESULTS OF PST USE IN AZERENERJI}

For the analysis of the efficiency of PST application in the considered $220 / 110 \mathrm{kV}$ power district, comparative calculations are given for the following options:

a) the case of PST absence;

b) the case of PST installation in the autotransformer circuit at the "Shimal-1" and "Shimal-2" power plants.

Let's consider the case of PST absence. As indicated above, in the normal scheme in various circuit-mode situations (disconnection of PTL 4 of $110 \mathrm{kV}$ "Shimal", simultaneous disconnection of PTLs 1 and 4 of $110 \mathrm{kV}$ "Shimal", disconnection of PTLs 1,4 of $110 \mathrm{kV}$ "Shimal" and PTL 3 of $220 \mathrm{kV}$ "Govsan", etc. ) the load of PTL 5 of $110 \mathrm{kV}$ "Shimal", depending on the air temperature, may exceed the permissible limit and, as a result, the complete output of the plant's power will be impossible. At the same time, the volume of restrictions, depending on the season and the load mode, is approximately 60 MW (6.25\% of the installed capacity of power plants).

The results of the power flow calculation for the elements of the adjacent electrical networks of the power district for normal scheme in the absence and in the presence of PST, respectively, have shown that the power losses are $65.73 \mathrm{MW}$ or $2.05 \%$ of the generation power and $64.62 \mathrm{MW}$ or $2.02 \%$ of the generation power.

The calculations have been performed on the basis of the measurement data of the summer maximum period and, at the same time, the generation in the power system was $3199 \mathrm{MW}$ and $829 \mathrm{MVAr}$, and the consumption was 3129.7 MW and 1663.7 MVAr.

Current load profiles of the branches according to the normal scheme with and without PST are presented in
Fig.5. As is obvious, when the PST is installed at "Shimal" PP, the current loads of PTLs 4,5 of $110 \mathrm{kV}$ "Shimal" reduce from 390 A to 260 A, while the degree of power loss reduction is $1.7 \%$. The current loads of other $110 \mathrm{kV}$ PTLs also decrease and the load of the adjacent networks is relatively equalized. The current load of the PTLs 3,4 of $220 \mathrm{kV}$ "Govsan" increases from $320 \mathrm{~A}$ to $370 \mathrm{~A}$, and in the PTL 3,4 $220 \mathrm{kV}$ "Zabrat" to $280 \mathrm{~A}$.

The above results correspond to the switch position of the transverse part of the PST $K_{t}=3$ and the obtained results are more clearly defined when regulating the branching of the transformer. The "current profiles switch position" relationship can be seen in Fig. 6. As is obvious from Fig. 4, by changing the position of the PST switch, the load of the PTLs 4,5 of $110 \mathrm{kV}$ "Shimal" can be reduced by $82.1 \%$.

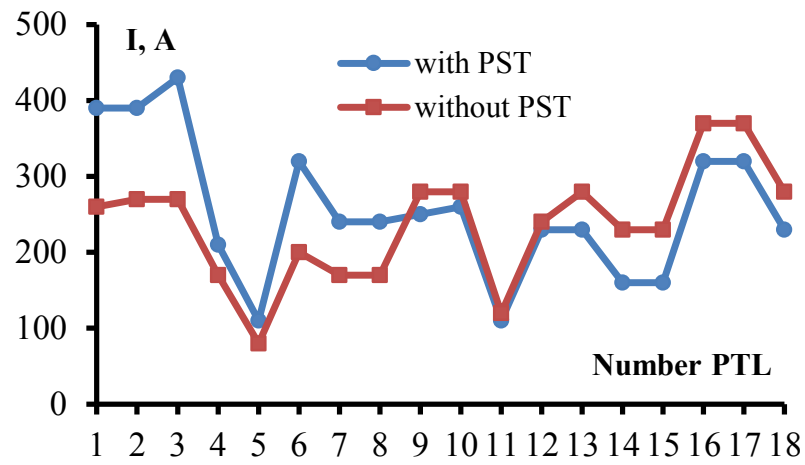

Fig. 5. Current profiles for branches of energy region according to normal diagram in cases of the presence and absence of PST

The change in power losses depending on the switch position is shown in Fig.7 and tendency to reduce losses in the networks is visible.

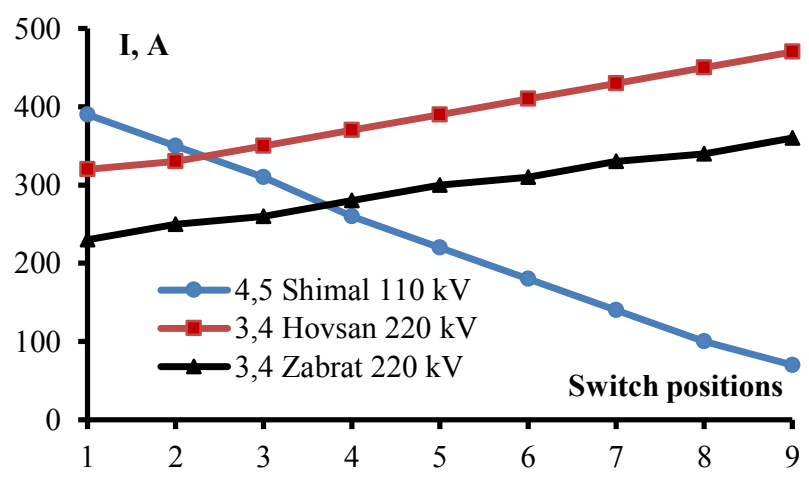

Fig.6. The current values of PTL depending on the position of the PST switch

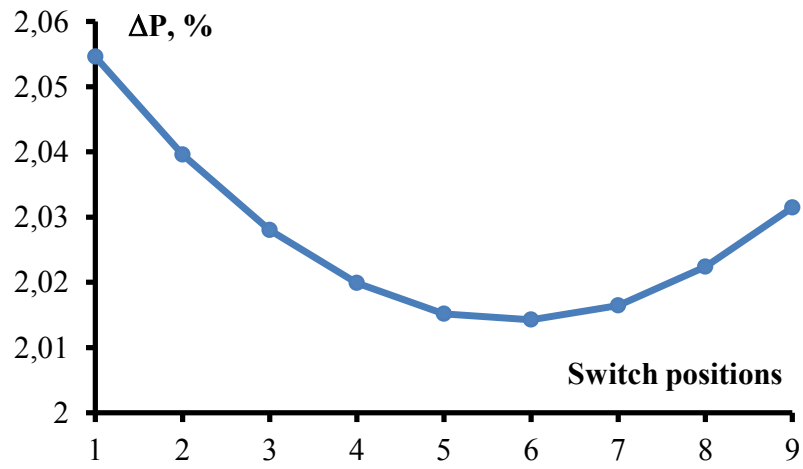

Fig.7. The dynamics of changes in the active power losses during PST operation 
Thus, by performing forced power distribution in the power district using PST, it is possible to significantly reduce the loads of $110 \mathrm{kV}$ PTLs and at the same time ensure efficient power flow in the adjacent electrical networks of the power district under consideration. Accordingly, this eliminates the need to apply any restrictions in various circuit-mode situations.

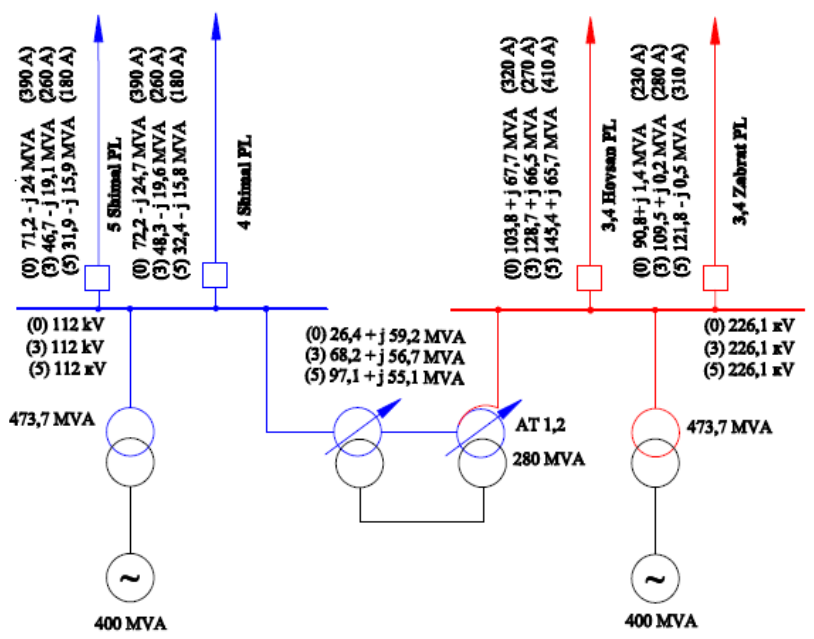

Fig.8. Distribution of powers generated from the buses of "Shimal-1" PP and "Shimal-2" PP through 110 and $220 \mathrm{kV}$ PTLs using PST

To assess the effectiveness of the PST application, the results of the values of active and reactive flows through 110 and $220 \mathrm{kV}$ lines, produced from the buses of the "Shimal-1" and "Shimal-2" power plants, as well as through communication autotransformers in three positions of the PST switch are shown in Fig. 8. As is obvious, change of the position of the PST switch significantly increases the transmitted powers through the lines 3,4 of $220 \mathrm{kV}$ "Govsan" and lines 3,4 of $220 \mathrm{kV}$ "Zabrat", while the transmitted powers through the PTLs4,5 of $110 \mathrm{kV}$ "Shimal" decrease. These and the above results confirm the effectiveness of PST application to ensure efficient power flow in this $220 / 110 \mathrm{kV}$ power district of the Azerbaijan power system. Considering the level of damage from the application of restrictions in various circuit-mode situations (about $\$ 4.5$ million) and the cost of PST, including the installation price (\$ 4.5-9 million), one can assume that the payback is about 1-2 years.

\section{CONCLUSIONS}

1. The natural irrational distribution of the powers of the adjacent electrical networks in the $220 / 110 \mathrm{kV}$ power district of the Azerbaijan power system causes uneven loading of PTLs of different voltages. The degree of heterogeneity through the network branches is determined, which reaches about 12 .

2. It has been determined that the transition to forced power distribution can provide the efficient power flow for the power district under consideration. For this purpose, option of PST application in the circuit of communication autotransformers installed between the
$220 \mathrm{kV}$ and $110 \mathrm{kV}$ buses of the "Shimal" $\mathrm{PP}$ is considered

3. For the assessment of the efficiency of PST application, studies for the power flow were carried out under various circuit-mode situations. The obtained results of computational experiments confirm the need to install the PST in the circuit of communication autotransformers of 220/110 kV "Shimal" PP.

\section{REFERENCES}

1. Pospelov G.Y., Fedin V.T., Lyrev P.V. Electrical systems and networks. Minsk., "Techno-irikt" UP, 2004, p. 720 .

2. Tirupathi R, Aruna G, Khan M.I., Ramesh K. Application of Phase Shifting Transformer in Indian Power System // International Journal of Computer and Electrical Engineering, Vol.4, No. 2, April 2012, pp. 242-245.

3. Kalinin L.P., Zaitsev D.A., Tirsu M.S., Qolub I.V. The Opportunities for Efficiency Increase of PhaseShifting Transformers in Power Transmission Operational Modes // 2019 IEEE PES Innovative Smart Grid Technologies Europe (ISGT-Europe). doi: 10.1109/ISGTEurope-2019.890548029 Sept.-2 Oct. 2019, Bucharest, Romania, pp. 1-5.

4. Verboomen J., Van Hertem D. Phase shifting transformers: Principles and applications, in Future Power Systems (FPS), Amsterdam, the Netherlands, November 2005, p.6.

5. Thomas J. Morrell, Jeff G. Eggebraaten. Applications for Phase-Shifting Transformers in Rural Power Systems // 2019 IEEE Rural Electric Power Conference (REPC). doi: 10.1109/REPC.2019.00020, 28 April-1 May 2019, Bloomington, MN, USA, pp.70-74

6. Brilinsky A.S., Kritsky V.A., Smirnova L.S. Features of the use of phase-shifting complexes in electric power systems // News of the Scientific and Technical Center of the United Energy System. Moscow, 2018, No. 1 (78), pp. 6-10.

7. Dobrusin L.A. Trends in the use of phase-shifting transformers in the electric power industry // Energoexpert, 2012, No. 3, pp.50-57.

8. Youssef R.D. Phase-shifting transformers in load flow and short-circuit analysis: modelling and control // IEE Proceedings C - Generation, Transmission and Distribution, Vol. 140 , Iss. 4 , July 1993, pp.331-336.

9. José M. Cano, Md. Rejwanur R. Mojumdar, Joaquín G. Norniella, Gonzalo A. Orcajo. Phase shifting transformer model for direct approach power flow studies // Electrical Power and Energy Systems, 2017, Vol.91, pp.71-79.

10. Thatarad S., Kiatiyuth K. Load Alleviation in Transmission System by Using Phase Shifting Transformer // 2018 International Electrical Engineering Congress (iEECON). 7-9 March 2018, Krabi, Thailand.

11. Thompson M. Protection System for Phase-Shifting Transformers Improves Simplicity, Dependability, and Security // 39 ${ }^{\text {th }}$ Annual Western Protective Relay Conference, May 2015, p.13. 
12. Brilinsky A.S., Evdokunin G.A., Kritsky V.A., MatviyenkovYu.V., Sidelnikov A.P., Smirnova L.S. Phase-shifting transformer in the power generation scheme of a large hydropower station // Izvestiya STC of the United Energy System. Moscow, 2019, No. 1 (80), pp. 6-14.

13. Aleksey B. Phase-shifting transformers: Keys to the efficiency of backbone and distribution networks. [Electronic resource]. Access mode: http://www.energovector.com/energoznaniefazopovorotnye-transformatory.html

14. Manolis B., Keith R., BellW. Use of phase-shifting transformers on the Transmission Network in Great Britain // 45 $5^{\text {th }}$ International Universities Power Engineering Conference UPEC2010. 31 Aug.-3 Sept. 2010, Cardiff, Wales, UK.

15. Evdokunin G. et al. Phase-shifting transformer was first used in the CIS in Kazakhstan // News of Electrical Engineering, 2008, No. 6 (48), pp.12-16.

16. Vizca P., Sejid T., Tomislav T. Power Flow Redistribution in Creation Power System Network using Phase-Shifting Transformer // (2015) Research Gate

https://www.researchgate.net/publication/274391037, Doi:1013140/RG2.1.2541.7765, University of Zagreb, p. 17 .

Thsis work was supported by the Science Development Foundation under the President of the Republic of Azerbaijan -

Grant № EIF-BGM-4-RFTF-1/2017-21/09/1 